\title{
Rhabdomyolysis in a chronic kidney disease patient after lung surgery
}

\author{
Myong-Su Chon ${ }^{1}$, Woo-Jong Shin ${ }^{1}$, Sang-Yoon Cho ${ }^{1}$, Ji-Hyun So ${ }^{1}$, and Soon-Ho Chon ${ }^{2}$ \\ Departments of ${ }^{1}$ Anesthesiology and Pain Medicine, ${ }^{2}$ Thoracic and Cardiovascular Surgery, College of Medicine, Hanyang University, \\ Seoul, Korea
}

Rhabdomyolysis is the rapid lysis of the rhabdomyoma due to muscular tissue damage, which leads to circulation of myoglobin, which causes nonspecific clinical syndromes [1]. Rhabdomyolysis can occur post-traumatically or from metabolic derangements [1]. Rhabdomyolysis is a well-known cause of acute renal failure (ARF), but in patients with chronic kidney disease (CKD), the characteristic symptoms of rhabdomyolysis are not so obvious and variations in biochemical tests can be similar to CKD patients [2]. We report a CKD patient who developed rhabdomyolysis after a lung surgery under general anesthesia.

The patient was a diabetic 64 -year-old male who was receiving intermittent hemodialysis after being diagnosed with CKD a year ago. He was taking aspirin and clopidogrel due to a right thalamic infarction; irbesartan, isosorbide dinitrate, and nifedipine for high blood pressure; and insulin due to diabetes. After one year observation of a $2 \mathrm{~cm}$ nodule discovered in his left lingular segment at the time of CKD diagnosis, small cell lung carcinoma and adenoma was diagnosed. A left lingular segmentectomy of upper lobe by thoracotomy was scheduled. Patient received hemodialysis 36 hours before surgery, and laboratory data showed a $\mathrm{Ca}^{2+}$ level of $8.5 \mathrm{mg} / \mathrm{dl}, \mathrm{K}^{+} 5.6 \mathrm{mEq} / \mathrm{L}$, phosphate 5.1 $\mathrm{mg} / \mathrm{dl}$, urea $58 \mathrm{mg} / \mathrm{dl}$, creatine $11.0 \mathrm{mg} / \mathrm{dl}$, albumin $4.1 \mathrm{~g} / \mathrm{dl}$, uric acid $8.7 \mathrm{mg} / \mathrm{dl}$, and CK $91 \mathrm{U} / \mathrm{L}$ (Table 1). There were no signs of $\mathrm{K}^{+}$elevation in electrocardiogram.

Tracheal intubation was done with a left sided double lumen tube using pentothal sodium $250 \mathrm{mg}$. Atracurium 30 $\mathrm{mg}, 1 \%$ lidocaine $80 \mathrm{mg}$ and fentanyl $100 \mu \mathrm{g}$. Anesthesia was maintained using 2.0-6.0 vol\% desflurane with $100 \%$ oxygen and remifentanil. Mechanical ventilation was started with a tidal volume of $450 \mathrm{ml}$ at a frequency of 15 per minutes. Total time under general anesthesia was 285 minutes; systolic blood pressure was maintained between 100 and $130 \mathrm{mmHg}$ and diastolic blood pressure was maintained between 60 and $80 \mathrm{mmHg}$. Body temperature was kept around $36.0^{\circ} \mathrm{C}$. To maintain muscle relaxation during surgery, injection of atracurium was started 15 minutes after intubation. About 30 minutes after one lung ventilation, the patient's $\mathrm{SpO}_{2}$ suddenly decreased. Arterial blood gas analysis (ABGA) showed a $\mathrm{pH}$ of 7.39, $\mathrm{PaCO}_{2} 32 \mathrm{mmHg}, \mathrm{PaO}_{2} 51 \mathrm{mmHg}, \mathrm{BE}-5.1 \mathrm{mEq} / \mathrm{L}$, $\mathrm{Na}^{+} 137 \mathrm{mEq} / \mathrm{L}, \mathrm{K}^{+} 7.15 \mathrm{mEq} / \mathrm{L}$ and $\mathrm{Ca}^{2+} 1.11 \mathrm{mg} / \mathrm{dl}$. One gram of calcium gluconate, 5 units of insulin, and $40 \mathrm{mEq}$ of sodium bicarbonate were immediately injected to prevent side effects from hyperkalemia. Results of additional ABGA showed pH 7.41, $\mathrm{PaCO}_{2} 30 \mathrm{mmHg}$. $\mathrm{PaO}_{2} 72 \mathrm{mmHg}, \mathrm{BE}-3.9 \mathrm{mEq} / \mathrm{L}$, $\mathrm{Na}^{+} 139 \mathrm{mEq} / \mathrm{L}, \mathrm{K}^{+} 6.30 \mathrm{mEq} / \mathrm{L}, \mathrm{Ca}^{2+} 1.08 \mathrm{mg} / \mathrm{dl}$, and blood sugar test at 187. One gram of calcium gluconate, 5 units of insulin, and $40 \mathrm{mEq}$ of sodium bicarbonate were additionally administered. Operation time was 210 minutes. After surgery, patient was moved to intensive care unit (ICU) and 2 hours after surgery (operative day), his $\mathrm{K}^{+}$level measured $5.6 \mathrm{mEq} / \mathrm{L}$. Nine hours later (postoperative day 1), it increased to $8.9 \mathrm{mEq} /$ $\mathrm{L}$, so calcium gluconate and polystyrene sulfonate calcium were administered and kalimate enema was done (Table 1). Eleven hours after surgery, $\mathrm{K}^{+}$level increased again $(8.9 \mathrm{mEq} / \mathrm{L})$, thus, continuous renal replacement therapy (CRRT) was done. At the

Corresponding author: Woo-Jong Shin, M.D., Ph.D., Department of Anesthesiology and Pain Medicine, Hanyang University Guri Hospital, 249-1, Gyomun-dong, Guri 471-701, Korea. Tel: 82-31-560-2390, Fax: 82-31-563-1731, E-mail: swj0208@hanyang.ac.kr

(c) This is an open-access article distributed under the terms of the Creative Commons Attribution Non-Commercial License (http:// creativecommons.org/licenses/by-nc/3.0/), which permits unrestricted non-commercial use, distribution, and reproduction in any medium, provided the original work is properly cited. 
Table 1. Perioperative Laboratory Data

\begin{tabular}{|c|c|c|c|c|}
\hline & Op day & POD 1 day & POD 2 day & POD 10 day \\
\hline Calcium (mg/dl) & 8.5 & 8.2 & 8.7 & 4.5 \\
\hline Phosphorus (mg/dl) & 5.1 & 6.3 & 4.2 & 56 \\
\hline BUN (mg/dl) & 58 & 68 & 58 & 8.3 \\
\hline $\mathrm{Cr}(\mathrm{mg} / \mathrm{dl})$ & 11.0 & 10.4 & 8.0 & 4.7 \\
\hline Potassium (mg/dl) & 5.6 & 8.9 & 7.4 & 61 \\
\hline $\mathrm{CPK}(\mathrm{U} / \mathrm{L})$ & & & 1,948 & 282 \\
\hline Myoglobulin (ng/ml) & & & 5,815 & \\
\hline CK-MB (ng/ml) & & & 15.2 & \\
\hline Uric acid (mg/dl) & 8.7 & & & \\
\hline
\end{tabular}

Op: operation, POD: postoperative day.

second postoperative day, $\mathrm{K}^{+}$level increased again to $7.4 \mathrm{mEq} /$ L. At this time possibility of rhabdomyolysis was suspected so supplementary laboratory test were done in which CPK, myoglobin and CK-MB levels were 1,948 U/L, 5,815 ng/ml and $15.2 \mathrm{ng} / \mathrm{dl}$, respectively; thus, rhabdomyolysis was diagnosed and hemodialysis and hydration were done. Common clinical symptoms of muscle swelling or pain seen in rhabdomyolysis were absent in the patient. Ten days after surgery, CPK decreased to normal range (61 U/L) and myoglobin kept decreasing $(282 \mathrm{ng} / \mathrm{ml})$. The patient was moved from the ICU to the general ward (Table 1 ).

Diagnosis of rhabdomyolysis may be masked in CKD patients due to the fact that the characteristic clinical symptoms of this syndrome such as muscle pain or weakness and darkbrown urine are absent $[1,2]$. CKD patients may not display the characteristic biochemical changes and symptoms of rhabdomyolysis because metabolic disorders due to CKD include hyperphosphatemia and hypocalcemia, and patients who receive dialysis commonly display hyperkalemia and increased CPK after surgery [2]. Therefore, recognition and diagnosis of rhabdomyolysis in a CKD patient can be difficult and elusive $[1,2]$.

We can not say for sure when rhabdomyolysis started in our patient because biochemical blood tests to confirm it was done in the second day after surgery. Laboratory analysis showed a CPK (1,948 IU/L) 5 times higher than normal [1,3], myoglobin $(5,815 \mathrm{ng} / \mathrm{ml})$ more than 83 times higher, and CK-MB (15.2 ng/ $\mathrm{ml})$ more than 3 times higher. Phosphate $(6.3 \mathrm{mg} / \mathrm{dl})$ increased, but $\mathrm{Ca}^{2+}(8.5 \mathrm{mg} / \mathrm{dl})$ was within the normal range, probably because the patient was injected with calcium during surgery and in ICU. The medications used in our patient regarding anesthesia had little association with rhabdomyolysis $[2,4]$. Considering the fact that our patient received hemodialysis 36 hours before surgery, electrolyte disorders as a possible cause of it is unlikely. Also medications that our patient was taking, are not related with rhabdomyolysis [2]. Myoglubinuria and rhabdomyolysis has been reported in CKD patients after undergoing surgery in the supine position for 8 hours and after undergoing surgery in the lateral position for over 4 hours $[3,5]$. The patient in our case underwent general anesthesia in left lateral position for more than 4 hours and considering the history of cerebral infarction, it could be the cause for rhabdomyolysis.

In conclusion, recognizing rhabdomyolysis induced ARF due to traumatic or non-traumatic muscle damage is relatively easy, but in CKD patients, diagnosing rhabdomyolysis is not so obvious because the characteristic symptoms and biochemical findings are masked by CKD itself. Especially, in CKD patients who show increased CK-MB and myoglobin, the possibility of rhabdomyolysis should not be overlooked, regardless of how small or big the operation may be.

\section{References}

1. Bagley WH, Yang H, Shah KH. Rhabdomyolysis. Intern Emerg Med 2007; 2: 210-8

2. Ori Y, Korzets A, Gruzman C, Chagnac A, Zevin D, Weinstein T, et al. Postoperative rhabdomyolysis in patients with end-stage renal failure. Am J Kidney Dis 1998; 31: 539-44.

3. Lee GY, Lee H, Kim YJ. Rhabdomyolysis recognized after elevation of liver enzymes following prolonged urologic surgery with lateral decubitus position -a case report. Korean J Anesthesiol 2011; 61: 341-3.

4. Muto S, Tabei K, Asano Y, Hosoda S. A case of rhabdomyolysis in chronic renal failure. Jpn J Med 1987; 26: 76-80.

5. Alterman I, Sidi A, Azamfirei L, Copotoiu S, Ezri T. Rhabdomyolysis: another complication after prolonged surgery. J Clin Anesth 2007; 19: 64-6. 